\title{
Spontaneous Gesturing in the EFL Classroom and its Impact on Interaction and Learning: A Case Study
}

\author{
Haifa H AlGhamdi (Corresponding author) \\ English language Institute, King Abdulaziz University (KAU) \\ Jeddah, Saudi Arabia \\ E-mail: haifaahg@live.com \\ Fatimah M A Alghamdi \\ English language Institute, King Abdulaziz University (KAU) \\ Jeddah, Saudi Arabia \\ E-mail: fmalghamdi@kau.edu.sa
}

Received: July 12, 2017 Accepted: July 28, 2017 Published: July 29, 2017

doi:10.5296/ijele.v5i2.11616 URL: https://doi.org/10.5296/ijele.v5i2.11616

\begin{abstract}
The purpose of this study is to explore the effect of English as a Foreign Language (EFL) teachers' spontaneous use of non-verbal gesture cues in classroom atmosphere and in teaching and learning English vocabulary at college, EFL Saudi context. Two groups consisting of thirty-nine female students, who are studying in their preparatory year at a major Saudi university, and two female EFL teachers participated in the study. For one session each, the two groups were observed by one of the researchers and an independent observer. Each of the two groups' teachers was observed while teaching her subject matter to students where the students had to learn a list of new English vocabulary items. Qualitative data from the classroom observation sessions were gathered to identify possible differences in nonverbal behavior and to explore its effect on classroom interaction and general atmosphere. Quantitative data, on the other hand, was gathered through vocabulary tests to find out if different EFL teachers' nonverbal conduct will impact vocabulary learning. The findings of the study revealed that gesture has a positive impact on classroom interaction. Moreover, gesture has a significant impact on the EFL students' vocabulary retention. Based on the data anlysis and findings of this study, several implications are made on the topic of gesture and its impact on language learning and classroom interaction for further research and classroom practices.
\end{abstract}

Keywords: nonverbal, gesture, spontaneous gesturing, classroom interaction, vocabulary retention, Saudi EFL context 


\section{Introduction}

As EFL educators, we are not always aware of the significance of communication strategies that involve modalities of gesture and non-verbal body movements. We probably do not use them effectively, nor do we teach our students to use them in order to enhance their communication or language attainment. Although we intuitively know that the students are predisposed to reading nonverbal cues, we rarely make systematic use of nonverbal communication strategies. In many cases, when we face difficulties in getting a target language concept through to our students, we either exert more efforts in illustrating and exemplifying it, using more complicated linguistic items, or choose the easiest way out: switching to the students' first language.

Teachers' effective use of non-verbal cues, specifically gestures, in English as a Second Language (ESL) or English as a Foreign Language (EFL) classrooms, is believed to make the environment of the classroom more encouraging and inviting. It is also believed to help in facilitating students' comprehension and language acquisition. Therefore, researchers support the idea that language teachers need to be trained explicitly to become aware of their gesture use (Allen 2000; Barnett 1983; Sime 2006). This study was carried out to explore the role of gesture in enhancing classroom interaction and facilitating language learning.

\subsection{Rationale and Context of the Study}

This study was conducted in the context of a tertiary level, English language Institute (ELI) at a major Saudi university, among EFL students and teachers of the preparatory year program. Students in this year are initially placed in one of four proficiency levels that correspond to the following designated language proficicency levels: B, B1, A and A1 of the Common European Framework of Reference for Languages (CEFR). The aim behind the preparatory year program is to enroll freshman students in intensive English language and basic sciences' courses which occupy a daily schedule that sums up to twenty-seven hours a week, eighteen hours of which is spent in English language classrooms. This intense amount of classroom time has its impact on students' attitude and behavior inside the classroom.

Teachers at the ELI have often remarked on students' lack of interest in learning and many have attributed this to students' lack of intrinsic motivation that can only be invoked by the students themselves. Some have also attributed this lack of interest to the long class hours which could extend to three or four hours in a single session. Remedial sessions and of course teachers' efforts to contain the problem have often fallen behind in promoting positive attitudes or helping the students to achieve more success in English language learning. Therefore, there is a need to investigate the effectiveness of other unconventional teaching strategies in raising and sustaining students' interest and assisting their comprehension and retention of language skills, items and structures.

Influenced by the relevant literature on the impact of non-verbal gesture cues in promoting communication and assisting learning, the authors aimed at exploring, first, the extent at which gesure is used in the EFL classrooms in the particular context of college preparatory year English program and if EFL teachers of different backgrounds, English language native 
speakers and Arab language native speakers, EFL teachers would differ in their use of gesture. The following section lists the research questions which are guided by our investigation. .

\subsection{Research Questions}

1. To what extent are nonverbal cues used differently by two teachers, of different backgrounds, in college preparatory year EFL classrooms?

2. Do different teacher nonverbal profiles impact classroom interaction differently?

3. To what extent does the use of nonverbal communication strategies in the EFL classroom impact students' comprehension and retention of the target vocabulary?

\subsection{Literature Review}

Studies have shown that almost two thirds of meanings in human interaction are transmitted nonverbally (Birdwhistell, 1955; Philpott, 1983). According to Diana Mather in her book Secrets of Confident Communicators (2014), people make up ninety percent of their mind about someone in the first few seconds of their first meeting depending on (their nonverbal behavior) what their body says about them. "Regardless of the actual percentage, plenty of evidence documents that people rely heavily on nonverbal cues to express themselves and to interpret others' communication. Research shows that when verbal messages contradict nonverbal ones, adults usually believe the nonverbal messages over the verbal ones" (Burgoon, Floyd, \& Guerrero, 2010, p.3). This means that body movements, voice tone and facial expressions are far more important than the words people utter to convey a message. Although this appears to be a very sensitive and important topic to language teachers, academics and administrators, it has received little investigation thus far. As the belief in the need to undertake research on nonverbal communication in the applied linguistic field is rapidly growing, the significance of such research in foreign language learning, in particular, has been recently getting due attention..

\subsection{Nonverbal Gesture Cues}

According to Thornburry (2013), gesture is sought to be the bodily behavior that is most directly tied to linguistic meaning. It is inextricably linked to speech to form one integrated system. McNeill (2012) states that: "gestures and synchronous speech are co-expressive but not redundant: they express the same idea each in its own way - often each its own aspects of it" (p. 31). As it serves a communicative function, it also helps in regulating people's thoughts and talks. That is why "blind speakers gesture despite their lack of experience with gesture's communicative function, this is evidence that gesture has a function for the speaker and not merely for the listener" (Iverson \& Goldin-Meadow, 1997, p. 464).

\subsection{Gestures and Language Learning}

The findings to date indicate that second language learners use gesture more when speaking their L2 than when speaking their L1 (Gullberg 1998; Hadar et al. 2001; Jungheim 1995; Nobe 1993; Stam 2008). Moreover, McCafferty and Ahmed (2000) stated that Second Language (L2) learners possibly will use representational gestures as a way of mapping 
consciously onto lexical items when the meaning of the words is not clear, so as to facilitate a listener's comprehension.

In addition, "the gestures of others (including, of course, the teacher) may help make input comprehensible by, for example, 'speech parsing' - i.e. helping learners find 'the words in the noise" (Thornburry, 2013). Within the field of L2 gesture studies, some scholars who have recommended that teachers and native speakers of the target language interact nonverbally in a way similar to what is known as (foreigner talk), a register of speech that gives emphasis to significant aspects of the L2 at the linguistic and discursive level, trying to accommodate a noticed lack of proficiency from the side of L2 conversers. Utilizing gesture in this manner may be helpful to learners processing information in the target language in a way similar to foreigner talk Adams (1998).

The gesture's communicative use has also been credited to originating positive affect. In (2000) Allen reported that instructor's use of gesture in a foreign language (FL) classroom induced an uplifting atmosphere for learning. Also, Moskowitz (1976) found that FL teachers who were seen as outstanding by their students showed a greater frequency of nonverbal behaviors than other FL teachers. Additionally, Ward and von Raffler-Engel (1980) found out that when the L2 teacher used illustrators and nonverbal cues as erect posture and direct eye contact, pupils tended to be more attentive than when he did not act in such manners.

Furthermore, Morett (2014) was interested in the role of gesture in facilitating L2 word learning. She investigated the impact of gesture on three major cognitive processes: communication, encoding, and recall. The researcher chose to draw vocabulary items from the Hungarian language because of its unfamiliarity to the student participants. The participants learned 20 Hungarian words that some of them were accompanied with gesture, and some of them were not. Then, they were instructed to teach the vocabulary meanings to interlocutors who were as well unfamiliar with the Hungarian language. The results revealed that gesture combined with speech enhanced all of the three interrelated cognitive process mentioned above.

In addition, the chances to enhance comprehension by drawing on the mimetic properties of gestural imagery is possible due to the increased use of iconic and other gestures to demonstrate speech. This gesture usage has been typically linked with the L2 classroom (Adams 1998; Allen 2000; Barnett 1983; Henzl 1979; Lazaraton 2004; McCafferty 2002). On a similar topic, Allen (2000) claimed that the academic implications for her study, backs the idea that "physical demonstration is important for learners in lower-level classes" (p. 169) as a way to complement their narrow knowledge of the L2.

Hood (2011) concludes in the following much quoted paragraph from her chapter on 'Body Language in Face-to-face Teaching' by saying:

"From a pedagogical perspective, these embodied movements and syndromes of gestures function to guide students' attention, signaling shifts in what is salient for them in the teacher talk. Evident too is the extent to which body language can cue students into the values attached to certain information, and can expand or contract perceived space for 
their participation in the discourse. While some teachers are more or less gestural in the enactment of their pedagogic practice, in each of the classrooms studied body language was intrinsic to the teachers' interaction with the students. It contributes to building redundancy in meaning-making potential and to expanding the meaning potential available in the spoken discourse alone. The teacher's body language is also a resource in mediating between potential and actual meanings and as such is an intrinsic part of the process of scaffolding students' learning" (p.49).

\section{Method}

The participants of the study were thirty-nine female students and two of the ELI English language teachers (one native and one non-native speakers of English). Data was obtained during the last of the four academic modules of the preparatory year and the collection process took place during the first semester of the academic year (October 2016).

The study adopted a mixed methods study design through the use of quantitative and qualitative data in order to adhere to the three main questions guiding the study. Qualitative data was collected from on-site real-time observation sessions with two groups of students ("Group B" 19 students - with a native speaker of English) and ("Group A" 20 students with a non-native speaker of English teacher). Each lasting for one hour in order to conduct the case-study with two different teachers with two different backgrounds and compare their nonverbal gesture cues with each other. Also, investigate the impact of their gesture on their students' behavior and attitude. Quantitative data was gathered through vocabulary tests to measure students' performance of learned lessons (vocabulary lessons). The two groups were of the same level, following the same syllabus and textbook.

\section{Findings and Discusion}

Classroom observations provided data of an exploratory nature while vocabulary tests results gave a more of explicit and precise information regarding students learning performance.

\subsection{Classroom Observation}

Two observers attended one session for each group to explore and document teachers use of nonverbal gestures while teaching unplanned vocabulary items to their students. The observation method succeeded in finding answers for the first research question and in netting two classroom sessions where the amount and type of natural, spontaneous gesturing differed substantially. The two teachers observed (who will be referred to as teacher B and teacher A) offered a pretty good contrast in terms of how each of them uses gesture when instructing, how much each gesture represents and also, in terms of how each conducted her lesson in ways that either enhanced or diminished the overall opportunities for gesturing. Teacher B's (the English native teacher) approach enhanced several opportunities for gesturing (both her own and the students') while teacher A's (the Arabic native teacher) diminished these opportunities. This was because teacher B's approach was more discussion 
and interaction-based, whereas teacher A's approach focused on the students' attention more on reading texts and writing text. This difference in gesture use had its impact on students' behavior inside the classroom and on total classroom interaction.

Teacher B's lesson took advantage, from the beginning, of available visual representations in the textbook (she projected p.108 with its photos on the board) and her lesson even included a portion where the students performed a 'Charades'-like activity during which they only gestured. In contrast, teacher A had the students paying the most attention to written words on the whiteboard; that is, initially, they were not even looking at the photos and pictures in their textbooks. Subsequently, the group activity was to write sentences with those words. Reading and writing of the target vocabulary items were more dominant in teacher A's lesson.

The two teachers were pretty similar in terms of how they gestured, during those intervals when they were engaging with the class in spoken discussion of individual vocabulary items. Interactive/pragmatic gestures dominated, rather than iconic/depictive/pantomimic gestures, of which there were relatively few. These intervals of whole-class interactive discussion were fewer in teacher A's class than in teacher B's. Thus, her lesson ended up having overall less gesture than teacher B's.

As both observed teachers had different teaching styles, there was a difference in general classroom conduct. Gesture was more dominant in teacher B's class; while the teacher was explaining the vocabulary items, she used her gesture as much as used speech. Even though not all gestures were representational or iconic still her interactive gestures had its impact on her students. There was more interaction and discussion in this class; students were more enthusiastic and active throughout the lesson. On the other hand, teacher A's calm nature made the class calmer, and the students were more receptive to information.

The vocabulary items implemented in this study were easy to be performed by gestures and that's why even teacher's like teacher A whom can be considered as a low gesturer couldn't help but to gesture when explaining some of the words such as: fly over, high, deep, statue, cave.

According to Gullberg (2006):

"Gestures are subject to individual variation but also to noteworthy uniformity within groups. Simplifying this paradox, it is fair to say that individuals differ with respect to how many gestures they are likely to perform, whereas speakers within a speech community and culture are remarkably consistent with regard to when and how they gesture when communicative content and situation are kept constant. The observations of similarity within and differences between groups allow us to talk about gestural repertoires whose characteristics are driven by cultural conventions and norms as well as by the very structure of the language spoken"(p.107).

The second research question (RQ2): Different nonverbal language profiles impact classroom interaction differently.

With regards to the second question of this study, it is to be noted that students differed in 
their participation (in how much they participated and the nature of their participation) as well. In teacher B's class, students were more opened to participate and they were more daring to make mistakes. This can be due to the way teacher B carried herself; she smiled a lot and made friendly jokes with the students. However, in teacher A's class, students were grouped to do tasks as teams. Certain tasks were given to each group to be carried out and so they can only participate when they are done. Teacher A also had more serious expressions, and this may have hindered students' interaction. For example, when she asked them "do you know what does the word sacred mean?" one of the students was hesitant to answer even-though the teacher was encouraging her to speak. Also, at several times the students had correct responses to the teacher's questions but they were hesitant to raise their voices and share the answers.

In addition, the types of activities given to students in both groups affected the chances of gesturing. For instance, teacher B played a game with the students at the end of the lesson where one of the students can only gesture the words to her classmates and they in return respond with the right word. This type of activity is fun, light and highly interactive which resembles the teacher's teaching style.

Teacher A activities were more focused on reading and writing as mentioned earlier. She did not project anything on the wall, she used the whiteboard to write the vocabulary items with their meanings. She drew some of the words on the board for students to get the meaning instead of showing pictures or using gestures (words such as: waterfall, city-wall).

From the above report, it can be noticed that the two teachers do differ in their natural use of gesture. The native English speaker teacher can be considered as a high gesturer while the non-native English speaker teacher can be labeled as a low gesturer. The findings also indicated the positive impact of gesture on classroom interaction and students' behavior inside the classroom. This confirms to Allen (2000) findings, where he found that instructor's use of gesture in foreign language classrooms induced an uplifting atmosphere for learning.

The results of classroom observations also go in line with Clark's (2016) study, who concluded that gesture activities had a positive impact on student participation and classroom interaction.

\subsection{Vocabulary Tests}

The vocabulary tests were administered to investigate the impact of nonverbal communication strategies and clues in the EFL classroom on students' comprehension and retention of the target vocabulary. The quantitative data was gathered through vocabulary tests in order to provide answers for the third research question that guided this study. The vocabulary test consisted of fifteen selected-response items divided into three sections: first section: fill in blanks, second section: Multiple Choice Questions (MCQs) and third section: matching exercise. The total score of the test is fifteen (5 marks for each section). All the test items were weighted equally. Accordingly, each correct answer was given one point, zero points when the answer is incorrect or the test-taker gives no response. In order to answer the third research research question, a null hypothesis was formulated. 
H0: There is no significant impact of non-verbal communication strategies on students' comprehension and retention of the learned words.

Table 1 below provides information about the differences between the groups. It shows that the mean vocabulary scores for Group B is higher than Group A (low-gesturer teacher). The standard deviation in Group A is higher in spite of the less number of students.

Table 1. Group Statistics for Group A and Group B

\begin{tabular}{|l|l|l|l|l|}
\hline & Gesture Profile & N & Mean & Std. Deviation \\
\hline Vocabulary Scores & $\begin{array}{l}\text { Low-gesturing Teacher's } \\
\text { Group (A) }\end{array}$ & 15 & 10.4667 & 3.13657 \\
\cline { 2 - 4 } $\begin{array}{l}\text { High-gesturing Teacher's } \\
\text { Group (B) }\end{array}$ & 19 & 12.7368 & 2.23214 \\
\hline
\end{tabular}

Even though the test in teacher B's group took about ten minutes (which is less by 5 minutes from the allocated time for the test) due to the teacher's tight schedule, the students managed to outperform the other group who had time on their side. Independent sample t-test (Table 2) shows that the difference between the two groups is significant $(t=2.466, p>0.05)$.

Table 2. Independent Samples t-test

\begin{tabular}{|c|c|c|c|c|c|c|c|c|c|c|}
\hline & \multicolumn{2}{|c|}{$\begin{array}{l}\text { Levene's Test } \\
\text { for Equality } \\
\text { of Variances }\end{array}$} & \multicolumn{7}{|c|}{ t-test for Equality of Means } \\
\hline & & \multirow[b]{2}{*}{$\mathrm{F}$} & \multirow[b]{2}{*}{ Sig. } & \multirow[b]{2}{*}{$\mathrm{T}$} & \multirow[b]{2}{*}{ df } & \multirow{2}{*}{$\begin{array}{l}\text { Sig. } \\
\text { (2-taile } \\
\text { d) }\end{array}$} & \multirow{2}{*}{$\begin{array}{l}\text { Mean } \\
\text { Differenc } \\
\text { e }\end{array}$} & \multirow{2}{*}{$\begin{array}{l}\text { Std. Errol } \\
\text { Differenc } \\
\text { e }\end{array}$} & \multicolumn{2}{|c|}{$\begin{array}{l}95 \% \\
\text { Confidence } \\
\text { Interval of the } \\
\text { Difference }\end{array}$} \\
\hline & & & & & & & & & Lower & Upper \\
\hline \multirow[t]{2}{*}{$\begin{array}{l}\text { Vocabulary } \\
\text { Scores }\end{array}$} & $\begin{array}{l}\text { Equal } \\
\text { variances } \\
\text { assumed }\end{array}$ & 2.678 & .112 & -2.466 & 32 & .019 & -2.27018 & .92078 & $\begin{array}{l}-4.1457 \\
3\end{array}$ & $\begin{array}{l}-.3946 \\
2\end{array}$ \\
\hline & $\begin{array}{l}\text { Equal } \\
\text { variances } \\
\text { not } \\
\text { assumed }\end{array}$ & & & -2.369 & 24.399 & .026 & -2.27018 & .95818 & $\begin{array}{l}-4.2460 \\
5\end{array}$ & $\begin{array}{l}-.2943 \\
0\end{array}$ \\
\hline
\end{tabular}

Figure one below further illustrates the difference between the groups with Group B, whose teacher was identified as high gesturer, showing higher mean vocabulary scores than Group A, with the low-gesturing teacher. 


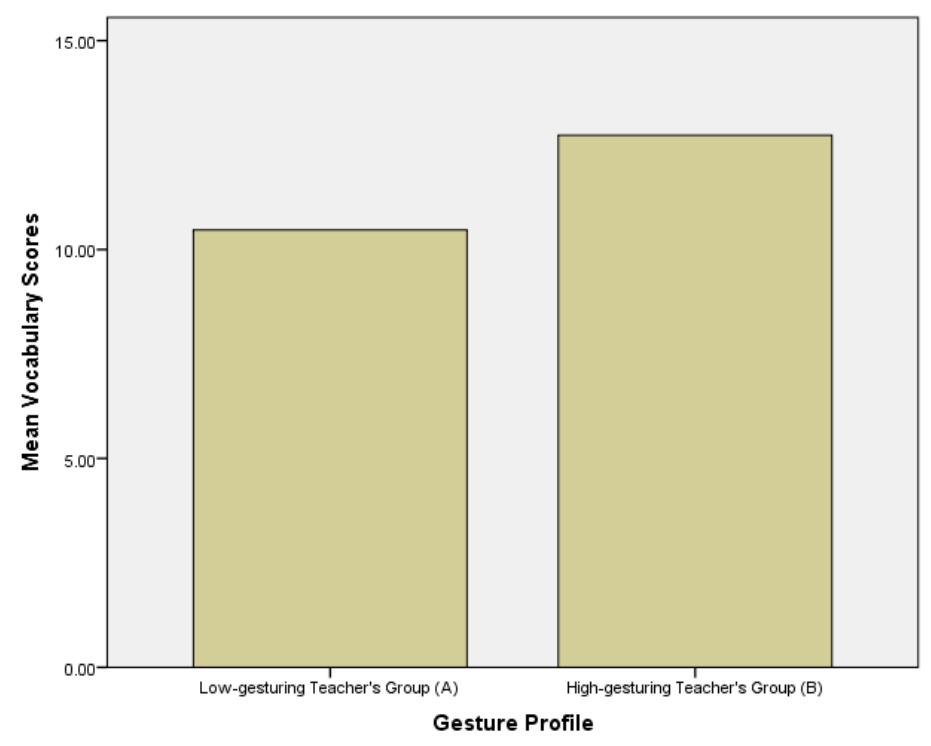

Figure 1. Mean Vocabulary Scores of Groups A and B

This indicates that gesture is a useful tool to assist student's comprehension and retention of learned vocabulary items. The findings of the quantitative data are in line with Morett's (2014), who found that gesturing in word learning has helped to encode the information and contributed to its retrieval.

\section{Limitations of the Study}

This study is of exploratory nature which makes it prone to limitations and lacking the power of generalizability. The selection of the two teachers to represent two backgrounds, native and nonnative, has ultimately masked other differences that exist between the two teachers and the two classrooms. Other variables were by no means controlled. However, the strength of such case-study, exploratory investigation is that it gives us insight into a practice that has never been explored in this particular context. The notion of probing how much gesture is used spontaneously by different teachers and how different nonverbal behavior profile is used is, besides its novelty, can form the bases on which we hypothesis about and set out to study the impact of teachers' nonverbal strategies on classroom interaction and learning. Moreover, the target material, i.e. the vocabulary items to be learned and tested, was not unified, nor were there any planning for unified lesson delivery methods, such as use of power point or text book material. Again, this was due to the exploratory nature of this investigation

\section{Conclusions and Implications for Teaching and Further Research}

The study in hand addresses issues of communication strategies and advocates for unconventional ones. Tight schedules, lack of experience, and difficulty of bringing in class technological equipments or aids have undesired impact on the teaching and learning process inside the classroom. As much as students are held responsible for their own learning, 
teachers have the responsibility in making the classroom environment joyful and inviting. Teaching strategies that involves gesture and embodiment are not only believed to enhance classroom interaction and general classroom environment, it is also believed to have great impact on students' linguistic performance. It is a readily available tool which teachers can implement in teaching and gain unprecedented advantages. The vocabulary tests and classroom observations indicated the many positive aspects of using gesture as a pedagogical tool. Observation data showed that teachers differed in their use of spontaneous gesture in the EFL classroom settings, and that the teacher who uses more gesture have promoted more engaging classroom environment. It is important to note, accordingly, that teachers need to be aware of their spontaneous use of gesture and what they nonverbally project to their students as this has a huge impact on the receivers and general classroom conduct. It is also recommended that teachers be trained to best use their gesture and teach their students to do so in order to make communication easier and more successful. Further research on gesture implementation need to be carried out with larger scope of teachers and students of both genders to yield more insightful conclusions as this study was limited to one context and one gender. Further research will also need to provide a model for measuring classroom interaction more accurately and control as many variables as possible, in order to measure the impact of gesture the learning process and product of EFL learners.

\section{References}

Adams, T. W. (1998). Gesture in Foreigner Talk. Unpublished dissertation, University of Pennsylvania.

Allen, L. (2000). Nonverbal accommodations in foreign language teacher talk. Applied Language Learning, 11, 155-176.

Barnett, M. A. (1983). Le langage des gestes. Canadian Modern Language Review, 41, 543550 .

Birdwhistell, R. L. (1955). Introduction to kinesics: An annotation system for analysis of body motion and gesture. Department of State, Foreign Service Institute.

Burgoon, J. K., Floyd, K., \& Guerrero, L. (2010, January). Nonverbal communication theories of interaction adaptation. In SAGE Publications Inc. https://doi.org/10.4135/9781412982818.n6

Clark, J. (2016). Teaching L2 vocabulary with student-and teacher-generated gestures: A classroom perspective. Unpublished doctoral dissertation, Concordia University, Faculty of Arts and Science.

Gullberg, M. (1998). Gesture as a Communication Strategy in Second Language Discourse. Lund: Lund University Press.

Gullberg, M. (2006). Some reasons for studying gesture and second language acquisition (Hommage à Adam Kendon). IRAL-International Review of Applied Linguistics in Language 
Teaching, 44(2), 103-124. https://doi.org/10.1515/IRAL.2006.004

2017, Vol. 5, No. 2

Hadar, U., Dar, R., \& Teitelman, A. (2001). Gesture during speech in first and second language: Implications for lexical retrieval. Gesture, 1(2), 151-165. https://doi.org/10.1075/gest.1.2.04had

Henzl, V. (1979). Foreigner talk in the classroom. International Review of Applied Linguistics, 17, 159-167.

Hood, S. (2011). Body language in face-to-face teaching: a focus on textual and interpersonal meaning. In Dreyfus, S., Hood, S., \& Stenglin, M. (eds.), Semiotic Margins: Meaning in Multimodalities, London: Continuum.

Iverson, J. M., \& Goldin-Meadow, S. (1997). What's communication got to do with it? Gesture in children blind from birth. Developmental Psychology, 33(3), 453. https://doi.org/10.1037/0012-1649.33.3.453

Jungheim, N. O. (1995). Assessing the unsaid: The development of tests of nonverbal ability. In J. D.

Lazaraton, A. (2004). Gesture and speech in the vocabulary explanations of one ESL teacher: A microanalytic inquiry. Language learning, 54(1), 79-117. https://doi.org/10.1111/j.1467-9922.2004.00249.x

McCafferty, S. G., \& Ahmed, M. K. (2000). The appropriation of gestures of the abstract by L2 learners. Sociocultural theory and second language learning, 199-218.

McCafferty, S. G. (2002). Gesture and creating zones of proximal development for second language learning. The Modern Language Journal, 86(2), 192-203. https://doi.org/10.1111/1540-4781.00144

Morett, L. M. (2014). When hands speak louder than words: The role of gesture in the communication, encoding, and recall of words in a novel second language. The Modern Language Journal, 98(3), 834-853. https://doi.org/10.1111/modl.12125

Moskowitz, G. (1976). The classroom interaction of outstanding foreign language teachers. Foreign language annals, 9(2), 135-143. https://doi.org/10.1111/j.1944-9720.1976.tb02639.x

Nobe, S. (1993). Cognitive process of speaking and gesturing: A comparison between first language speakers and foreign language speakers.Unpublished master's thesis, University of Chicago.

Philpott, J. S. (1983). The relative contribution to meaning of verbal and nonverbal channels of communication: A meta-analysis. Unpublished master's thesis, University of Nebraska, Lincoln.

Stam, G. (2008). What gestures reveal about second language acquisition. Gesture: Second Language Acquistion and Classroom Research, 231.

Thornburry, S. (2013, May 26). G is for Gesture [Web log post]. Retrieved June 14, 2017, 


\section{Macrothink}

from https://scottthornbury.wordpress.com/2013/05/26/g-is- for-gesture/

Ward, L., \& von Raffler-Engel, W. (1980). The impact of nonverbal behavior on foreign language teaching. Aspects of nonverbal communication, 287-304.

\section{Copyright Disclaimer}

Copyright for this article is retained by the author(s), with first publication rights granted to the journal.

This is an open-access article distributed under the terms and conditions of the Creative Commons Attribution license (http://creativecommons.org/licenses/by/3.0/). 